\title{
Dupla e múltipla pertença religiosa no Brasil
}

\author{
Claudio de Oliveira Ribeiro
}

\section{Resumo}

A pesquisa abordou as experiências de dupla ou múltipla pertença religiosa no Brasil. Metodologicamente, foram dados passos com distintas bases teóricas nos quais foram sistematizados os principais resultados da pesquisa. Isso se deu a partir da indicação de elementos que possibilitam avaliações mais apuradas dessas experiências, como: i) maior atenção ao destaque que o crescente quadro de pluralismo religioso tem para a vida das pessoas e grupos, o que lhes possibilita maiores informações e mais fácil acesso às diferentes propostas religiosas, ii) a importância de se pensar criticamente o quadro de pluralismo religioso, não a partir do conceito moderno de religião, em geral compartimentalizado, racionalizado e formal, mas a partir de como se dá efetivamente a relação entre vida cotidiana e expressões de fé, iii) a verificação de que tais experiências são vividas em espaços de fronteiras e nos entre-lugares das culturas onde brotam os novos signos que colaborarão e contestarão as definições e ideias sobre as sociedades, iv) o reconhecimento de que a matriz cultural e religiosa brasileira, devido ser ela marcada historicamente por elementos mágicos e místicos, fruto de uma simbiose das religiões indígenas, africanas e do catolicismo ibérico, facilita os processos de dupla ou múltipla pertença religiosa, e v) a constatação de que o trânsito religioso se dá, não apenas na migração de uma religião para a outra, mas também na recomposição simbólico-cultural de diferentes sistemas de crenças, o que torna um fator gerador de dupla ou múltipla pertença.

Palavras-chave: Múltipla pertença religiosa. Entre-lugares. Matriz religiosa brasileira. Trânsito religioso.

\section{Dual and multiple religious belonging in Brazil}

\section{Abstract}

The research approached the experiences of dual or multiple religious belonging in Brazil. Methodologically, were given steps with different theoretical bases in which the main results of the research were systematized. This was given from the indication of elements that enable more accurate evaluations of these experiences, such as: i) greater attention to the highlight that the growing framework of religious pluralism has for the lives of the people and groups, which enables them greater Information and easier 
access to the different religious proposals, ii) The importance of critically thinking the framework of religious pluralism, not having as starting point the modern concept of religion, in general compartmentalized, streamlined and formal, but from the relationship between everyday life and expressions of faith effective, iii) the verification that such experiences are lived in frontier spaces and in-between of the cultures where the new signs that will collaborate and contest definitions and ideas about societies, iv) the recognition that the Brazilian cultural and religious matrix, because it is historically marked by magical and mystical elements, result of a symbiosis of the indigenous, African and Iberian Catholicism, facilitates The processes of dual or multiple religious belonging, and v) The consideration that religious transit is given, not only in the migration of one religion to the other, but also in the symbolic-cultural recomposition of different belief systems; this reinforce the multiple belonging.

Key-words: Multiple religious belonging. In-between. Brazilian cultural and religious matrix. Religious transit.

\section{Doble y múltiple pertenencia religiosa en Brasil}

\section{Resumen}

La investigación abordó las experiencias de doble y múltiple pertenencia religiosa en Brasil. Metodológicamente, se dieron pasos con distintas bases teóricas en los que se sistematizaron los principales resultados de la investigación. Esto se dio a partir de la indicación de elementos que posibilitaron evaluaciones más exactas de estas experiencias, tales como: (i) mayor atención al destaque que el creciente cuadro de pluralismo religioso tiene para la vida de las personas e grupos, lo que les posibilita mayores informaciones y más fácil acceso a las diferentes propuestas religiosas, (ii) la importancia de pensar críticamente el cuadro de pluralismo religioso, no a partir del concepto moderno de religión, en general compartimentalizado, racionalizado y formal, sino a partir de cómo se da efectivamente la relación entre vida cotidiana expresiones de fe, (iii) la verificación de que tales experiencias son vividas en espacios de fronteras y en los entre-lugares de las culturas donde brotan los nuevos signos que colaboraron y contestaron las definiciones e ideas sobre las sociedades, (iv) el reconocimiento de que la matriz cultural y religiosa brasileña, debió ser marcada históricamente por elementos mágicos y místicos, fruto de una simbiosis de las religiones indígenas, africanas y del catolicismo ibérico, lo que facilita los procesos de doble o múltiple pertenencia religiosa, y (v) la constatación de que el tránsito religioso se da, no solo en la migración de una religión a otra, sino también en la recomposición simbólico-cultural de diferentes sistemas de creencias, lo que se torna un factor generador de doble y múltiple pertenencia.

Palabras claves: múltiple pertenencia religiosa, entre-lugares, matriz religiosa brasileña, tránsito religioso

\section{Introdução}

As análises sobre o quadro de pluralismo religioso no Brasil têm nos chamado a atenção para vários aspectos. Um deles é o que se denomina usualmente como "dupla”, ou "múltipla pertença religiosa”, de difícil 
compreensão e análise. Desejamos a seguir apresentar alguns aspectos que julgamos relevantes para caminhar nessa direção, reconhecendo os limites de nossas indicações para tão complexa avaliação.

Nossa pressuposição é que tais experiências em geral são ocultadas e, por isso, pouco avaliadas. Como o debate sobre pluralismo religioso tem se fortalecido em diversos campos, elas têm sido também pouco a pouco visibilizadas. No entanto, o maior ou menor grau dessa visibilidade e também o da devida compreensão dela depende de alguns fatores. Entre eles destacaremos primeiramente o valor conferido ao crescente quadro de pluralismo religioso, o que possibilita maiores informações e mais fácil acesso às diferentes propostas religiosas. Ou seja, no campo acadêmico, quanto mais se valoriza e se explicita o pluralismo, tanto mais nitidamente se observarão as múltiplas pertenças religiosas. De modo similar, no campo das vivências pessoais, quanto mais se dá valor ao pluralismo, tanto mais se multiplicam as experiências de múltipla pertença.

O segundo fator é a importância de se pensar criticamente o quadro religioso, não a partir do conceito moderno de religião, em geral compartimentalizado, racionalizado e formal, mas a partir de como se dá efetivamente a relação entre vida cotidiana e expressões de fé. Esse elemento é de fundamental importância, porque as experiências concretas de múltipla pertença religiosa, em geral, articulam expressões religiosas majoritárias, no caso do Brasil o cristianismo católico, com formas e vivências populares arraigadas na cultura, sobretudo a partir das raízes indígenas e afro-brasileiras. Essas, na maioria das vezes, possuem compreensões salvíficas de natureza cósmica, ou seja, encontram o sentido divino mais profundo na natureza e nas realidades cotidianas. O cristianismo, ao menos em suas formulações dogmáticas mais formais, mais facilmente compreendidas pelos esquemas modernos de análise, tende a oferecer formas religiosas de uma busca de Deus na História a partir de uma transcendência da vida e do ser humano. A dupla pertença religiosa nesse caso requer, para ser bem compreendida, certo distanciamento crítico do conceito moderno de religião.

O terceiro é a própria valorização das experiências de múltiplas pertenças religiosas por serem vividas em espaços de fronteiras e nos entre-lugares das culturas, em geral mais abertos ao novo e mais fortemente sinalizadores de potencialidades e de crítica social. Analisar as múltiplas pertenças religiosas a partir desse referencial é um esforço que procura dar visibilidade à experiências, grupos e posicionamentos que são gerados 
nos "entre-lugares", bordas e fronteiras das culturas e das esferas de institucionalidades. Articulado com tais ideias está o que temos denominado de princípio pluralista (RIBEIRO, 2017). Ele é um instrumento hermenêutico de mediação teológica e analítica da realidade sociocultural e religiosa que possibilita divergências e convergências novas, outros pontos de vistas, perspectivas críticas e autocríticas para diálogo, empoderamento de grupos e de visões subalternas e formas de alteridade e de inclusão, considerados e explicitados os diferenciais de poder presentes na sociedade. Nossa pressuposição é que o princípio pluralista, formulado a partir de lógicas ecumênicas e de alteridade, possibilita melhor compreensão da diversidade do quadro religioso e também das ações humanas. Não se trata apenas de uma indicação ética ou "catequética". Com ele, as análises tornam-se mais consistentes, uma vez que possibilitam melhor identificação do "outro", especialmente as pessoas e grupos que são invisibilizados dentro da lógica sociológica que Boaventura de Souza Santos (2010) chamou de "sociologia das ausências".

O quarto é o reconhecimento de que a matriz cultural e religiosa brasileira, devido ser ela marcada historicamente por elementos mágicos e místicos, fruto de uma simbiose das religiões indígenas, africanas e do catolicismo ibérico, facilita os processos de dupla ou múltipla pertença religiosa. Para se compreender as experiências de dupla ou múltipla pertença religiosa, é fundamental conhecer o caráter dinâmico e inclusivo da matriz religiosa e cultural brasileira. Esse referido amálgama cultural amplia-se nas últimas décadas ao compor-se com a substituição das religiões pela lógica religiosa do sistema econômico. Trata-se de um quadro de intensa complexidade.

Por fim, a constatação de que o trânsito religioso se dá, não apenas na migração de uma religião para a outra, mas também na recomposição simbólico-cultural de diferentes sistemas de crenças. Isso acontece em diferentes tipos de expressão religiosa: i) o que afirma determinada pertença e admite experimentar outras expressões religiosas, ii) o que, por motivos externos nem sempre confessáveis, declara uma religião mas exerce outra, iii) o que harmoniza e integra relativamente bem mais de uma tradição religiosa, iv) o que não adere uma religião específica, mas transita por mais de uma, e v) aquele que, mesmo mantendo a sua pertença religiosa, articula elementos simbólico-rituais de outras religiões.

Antes de avaliar tais fatores, permito-me uma nota pessoal. No diálogo com várias pessoas do meu círculo de amizade e de relacionamento 
tenho ouvido, direta e indiretamente, variados relatos que revelam um fato instigante. Trata-se da percepção de que o próprio termo "dupla ou múltipla pertença", embora muito usado academicamente, parece em boa parte das vezes não ser totalmente preciso, uma vez que as pessoas em questão nessas experiências não se sentem necessariamente como protagonistas de algo que seja duplo ou múltiplo. Há, por exemplo, muitas pessoas de Candomblé que se sentem cristãs e, de fato, não saberiam ser cristãs de outra forma que não esta: a que articula intimamente e com certa harmonização práticas de ambas as tradições. Trata-se de uma articulação interna do fiel como se fosse um diálogo espiritual de cada pessoa consigo mesma e com a totalidade da vida que está ao seu redor, incluindo vivências não explicitamente religiosas. Essa interação integradora possibilita um amálgama espiritual e santo que não é em si dupla pertença. É outro modo de se viver a fé, o que alguns chamam de uma espiritualidade transreligiosa (ARAGÃO, 2017). Michel Amaladoss (1995) nos chamara a atenção para o fato de que muitas vezes são os que representam sistemas religiosos formais ou instituições que acusam de sincretismo os que se aventuram pelo caminho da múltipla pertença, cujas práticas não se enquadram nos limites estabelecidos pelo sistema religioso formal. No entanto, as pessoas e grupos que possuem tais práticas ditas sincréticas encontram nelas uma unidade de sentido e não as veem como artificiais nem conflitantes. Por razões didáticas, não vamos nos deter nessa particularidade, deixando-a para outra oportunidade, embora ela esteja presente em várias observações que ora fazemos.

Atentemos, pois, aos aspectos inicialmente indicados:

\section{A visibilidade do pluralismo religioso como fator de facilitação da múltipla pertença religiosa.}

A crescente visibilidade e valorização do pluralismo religioso, não isenta de tensões, revela que uma parte das experiências religiosas é vivida, não apenas em uma única expressão religiosa, mas em duas ou mais tradições. Ao mesmo tempo, o fato de as diferentes expressões religiosas se tornarem mais conhecidas e públicas possibilita para as pessoas, em especial para a juventude, maior acesso a elas. Por vezes, esse fato se torna um elemento facilitador de, não somente formas de trânsito religioso, mas também de dupla ou múltipla vivência religiosa, uma vez que as propostas religiosas em geral são sedutoras e mobilizadoras na vida humana. Muitas delas se apresentam como complementares ou suplementares ou possuem uma dinamicidade 
não excludente. Nesse aspecto, o quadro de emergente pluralidade se torna velozmente ainda mais plural, na medida em que revela ou desvela novas possibilidades de experiência religiosa.

De fato, a vivência religiosa no Brasil, assim como em outras partes do globo, sofreu, nas últimas décadas, fortes mudanças. Alguns aspectos do novo perfil se devem, sobretudo: i) à afirmação religiosa indígena e afrobrasileira, em suas diversas matrizes, especialmente as formas de Umbandas, Candomblés e encantarias, e uma série de expressões culturais regionais, em sua maioria híbridas e recompostas, ii) à multiplicação e maior visibilidade dos grupos orientais, em toda a sua diversidade étnica e cultural, tanto as diferentes expressões de Budismo, de Xintoísmo e de Confucionismo, como as religiões recém-chegadas ao Brasil, como Seicho-No-Ie e a Igreja Messiânica, e outras como Fé Bahaí, a Hare Krishna, iii) à presença pública, embora minoritária, das diferentes expressões do Judaísmo e do Islamismo, iv) à força popular do Espiritismo Kardecista e às expressões espiritualistas e mágicas que se configuram em torno da chamada Nova Era, v) ao fortalecimento institucional dos movimentos católicos de renovação carismática, e vi) ao crescimento evangélico, em especial, o das igrejas e movimentos pentecostais. Todas essas expressões, além de outras, formam um quadro complexo e de matizes os mais diferenciados (RIBEIRO, 2014).

Notem que na descrição citada estão listadas apenas as expressões propriamente religiosas. Ou, como temos chamado: "as religiões como tais". O número de grupos que se expressam em formas híbridas, tanto em relação à conjugação de elementos de diferentes expressões religiosas, quanto a reunião de elementos seculares e culturais, como terapêuticos, de autoajuda, econômicos, midiáticos e de entretenimento, com aspectos e práticas religiosas é considerável e de difícil descrição. Muitos deles são localizados em experiências particulares de grupos específicos. Outros são pontuais no tempo, com pouca duração de existência ou com reorganização constante de nomes, práticas e lideranças.

Os dados estatísticos sobre a realidade religiosa brasileira são importantes na medida em que têm revelado a crescente diversificação dos grupos. É fato que eles, embora confiáveis, não dão conta de aspectos mais complexos da realidade cultural e religiosa brasileira como a dupla ou múltipla pertença religiosa, por exemplo. Isto porque as pessoas entrevistadas são levadas a dizer qual é "a" sua religião. Embora, na estrutura classificatória do Censo demográfico feito pelo governo federal, em 2010, por intermédio 
do Instituto Brasileiro de Geografia e Estatística (IBGE), haja uma opção para múltiplo pertencimento, não há uma forma de confirmação que valide a resposta. Isso causou certa fragilidade para a quantificação dos dados que registraram a inexpressiva porcentagem de 0,01 , o que corresponderia a pouco mais de 15 mil pessoas. Ou seja, a dupla ou múltipla pertença não foi efetivamente medida.

No entanto, para as nossas reflexões, um dos dados de destaque do mesmo censo é o expressivo decréscimo do número de pessoas que se declaram católicas, que passou de $89 \%$, em 1980 , para $64 \%$ da população brasileira, em 2010. Ligado a isso está o fato de outras pesquisas mostrarem que apenas 5\% desse número ser considerado "praticante", ou seja, pessoas que participam de alguma atividade religiosa coletiva pelo menos uma vez na semana. Esses números podem revelar uma possível quebra da hegemonia católica no país nas próximas décadas. Além disso, a situação de pluralismo religioso pode ser percebida justamente nessa diferença entre o declarado no censo e o concretamente vivenciado. Ou seja, aí residem formas de dupla ou múltipla pertença religiosa, trânsitos dos mais diversos tipos e outras reconfigurações do campo religioso. Também se encontram presentes aí determinados comportamentos sociais que, devido a questões de manutenção do status quo, fazem que alguns grupos se declarem católicos embora sejam, de fato, fiéis de religiões afro-brasileiras, historicamente subalternalizadas. O campo evangélico, que desde os anos de 1980 dava sinais de crescimento e diversificação, mantém-se, em 2010, com 23\% da população brasileira, sendo que uma parcela considerável desse grupo foi denominada pelo censo como "evangélicos não determinados". Essa classificação alcançou 4,8 \% da população; um número considerado altíssimo, especialmente se comparado com as religiões não cristãs, que não ultrapassam 3\% em todo o país. "Evangélicos não determinados" reúne uma variedade de situações desde o trânsito religioso contínuo entre esses mesmos grupos a formas não confessionais de vinculação religiosa, o que na linguagem comum se chamou dos "desigrejados". Embora não haja formas precisas de verificação, esse número alto de declarações, somado à mobilidade urbana, à força da internet e redes sociais virtuais, representa um bolsão para experiências de múltipla pertença.

A metodologia do censo também não permite definir com maior nitidez a pluralidade religiosa dentro de uma mesma família, fenômeno cada vez mais comum e crescente na realidade brasileira. O mesmo ocorre com 
grupos indígenas, onde a relação entre religião e cultura é complexa e não facilmente descrita e objetivada.

Nesse sentido, os dados quantitativos não são suficientes para uma análise mais apurada do panorama do pluralismo religioso brasileiro, onde as crenças e práticas são mais significativas do que o pertencimento formal ou institucional. As múltiplas pertenças religiosas, tanto as mais conscientes e explícitas quanto as de ordem sincrética ou de trânsito e de assimilação de ideias, valores e visões, se encontram no primeiro polo de significados. Isso se dá sobretudo pela força mobilizadora e pragmática que as expressões religiosas costumam ter na organização da vida cotidiana. As múltiplas pertenças possuem sensibilidades próprias que advêm de vivências profundamente arraigadas no cotidiano e nas relações sociais. Ao contrário do que se passa com a declaração religiosa exclusiva, a dupla ou múltiplas pertenças são difíceis de serem quantificadas (CAMURCA, 2014, p. 16).

Outro aspecto fundamental para o debate sobre o pluralismo religioso que o censo não se propõe a aferir são as tendências não explicitamente religiosas, mas que marcam o imaginário e o cotidiano do brasileiro como terapias holísticas, expressões mágicas e místicas particulares e de pequenos grupos, estruturas celulares ("pequenos grupos”) de organização eclesial, estas encontradas especialmente no campo protestante, e formas variadas de recomposição sincrética de cosmovisões católicas, espíritas, afro-brasileiras e orientais.

Outro dado que se destaca e reforça o pluralismo é o aumento do número de pessoas que se declaram sem religião, 8\%. Ele somente não está acima dos grupos católicos e evangélicos.

Portanto, as análises sobre o pluralismo religioso precisam, ao mesmo tempo, estarem atentas aos dados do censo demográfico, e também aos seus limites e lacunas. Além disso, não é uma fácil tarefa acompanhar as projeções para a atualidade dos dados de 2010, após quase uma década. O mesmo nós podemos dizer em relação a outras pesquisas localizadas, em geral efetuadas com objetivos bem específicos e regionais. Nesse sentimos, frisamos que em nossa reflexão os dados do censo estão pressupostos, mas não privilegiados, pelos motivos que acabamos de descrever. O que enfatizamos é que o quadro crescente de pluralismo religioso reforça novas experiências de múltipla pertença religiosa.

\section{O valor da relação entre vida cotidiana e expressões de fé.}

Um segundo elemento necessário para uma compreensão mais adequada sobre as duplas ou múltiplas pertenças religiosas está associado 
às críticas ao conceito moderno de religião. Se os instrumentais de análise levarem em conta as críticas à concepção moderna de religião, sobretudo como tal visão reduz "religião" a um "escaninho" compartimentalizado da vida, poderão compreender mais facilmente o quadro, muitas vezes ocultado, das experiências de dupla ou múltipla pertença religiosa. $\mathrm{Na}$ visão moderna ocidental, a religião seria um âmbito específico da vida (e não a vida como um todo ou algo integrado na totalidade dela). A religião seria o resultado de escolhas racionais, certamente não exclusivas, mas certo recorte institucionalizado e com uma organização sistematizada e formal (GIUMBELLI, 2014).

O universo simbólico das culturas brasileiras, especialmente no campo popular, não comporta essa rigidez e reducionismo. O pluralismo religioso que marca a sociedade na atualidade requer para a sua melhor compreensão uma crítica desse conceito moderno. Em geral, tal concepção olha as experiências religiosas dentro de um canon de racionalidade que determinou uma área específica da vida, sem levar em conta as experiências totalizantes, que moldam estilos de vida, culturas e formas de agir. Essa visão foi amalgamada com o desenvolvimento político e filosófico do que se convencionou chamar de o Ocidente.

Stuart Hall, figura de destaque dos estudos culturais, em seu livro Formations of Modernity (1992), articula a construção do "Ocidente", usando a criativa expressão "O Ocidente e o Resto" (West and Rest). Tal concepção é formada por um padrão de pensamento e de linguagem que, desde a sua gênese, é marcada por relações econômicas de dominação. As análises científicas a respeito do pluralismo religioso e sobre os decorrentes diálogos ou conflitos que emergem desse quadro não podem, ao nosso ver, prescindir dessa perspectiva. Mesmo porque, para se usar uma expressão popular: ninguém entende mais do "resto" do que os grupos que cultivam formas excludentes e sectárias que marcam as identidades rígidas, ideológicas e conflitivas presentes no cenário de pluralismo religioso. No entanto, mesmo as experiências de diálogo inter-religioso, ainda que abertas e marcadas por lógicas de alteridade, também estão sujeitas à reprodução dos imaginários que surgiram com a formação do Ocidente.

Nesse contexto de configuração de culturas, ocorre um duplo processo. O Ocidente é ao mesmo tempo um produto dos meios históricos de domínio, bem como, uma ferramenta/paradigma para exercer esse mesmo domínio. Nas palavras do autor: "A ideia de 'o Ocidente' tornou-se tanto o fator de 
organização em um sistema de relações globais de poder quanto o conceito de organização de uma forma total de se pensar e de se falar" (HALL, 1992, p. 187). Estamos diante de um sistema de representação e de um conceito cujo núcleo central está muito perto de uma ideologia. Essa construção ocorreu ao longo do processo de constituição e de desenvolvimento do sistema econômico capitalista (BENJAMIN, 2013). A crescente coesão interna que resultou de conflitos com outros povos e de contraste com o mundo externo contribuiu para se forjar um novo senso de identidade. A concepção religiosa europeia cristã é um dos elementos cruciais dessa coesão. Tal concepção marca nos dias de hoje diferenciais de poder que interagem diretamente nos imaginários e nas práticas decorrentes dos diálogos inter-religiosos, especialmente em função da participação de grupos religiosos constituídos por grupos subalternos, sobretudo os de matrizes afro-brasileiras.

Esse processo atravessou os continentes, sobretudo pelos empreendimentos coloniais e imperiais e selou o cristianismo ocidental com as marcas de domínio e de hegemonia, por vezes violenta, por vezes dissimulada. $\mathrm{Na}$ medida em que se fortalecem, nos diferentes continentes, formas de aproximação inter-religiosa entre grupos cristãos e de outras religiões, em geral, como já mencionado, mergulhadas em culturas subalternas, os elementos que marcam os diferenciais de poder entre elas precisam ser identificados, assumidos nos processos dialogais e equacionados de modo pertinente. Caso tal processo de identificação e equacionamento não seja feito, podem-se gerar formas artificiais de relacionamento entre os grupos, podendo inclusive ocultar novas formas de domínio.

Dentro do contexto de ressignificações do quadro cultural e religioso brasileiro, temos chamado a atenção para o fato do conceito moderno de religião, articulado com a noção ideológica do Ocidente, e em geral adaptado aos cristianismos tradicionais, não corresponder às necessidades de avaliações mais apuradas das religiões tradicionais e populares. Nesse sentido, consideramos urgente uma crítica ao conceito de religião visto nessa lógica moderna que, por ser compartimentalizado e não valorizar a complexidade e integralidade da vida, não favorece as compreensões mais orgânicas e integradoras dos espaços cotidianos, como é o caso de expressões religiosas afro-brasileiras e orientais, entre outras. Embora a cultura moderna tenha se autoafirmado a partir de um discurso pretensamente secular e secularizante - ao buscar uma delimitação do espaço específico da religião - o que as análises têm mostrado é um deslocamento do religioso para fora de suas 
esferas tradicionais, podendo ser identificado nas práticas econômicas, nas formas de entretenimento, na busca de soluções para questões concretas da vida cotidiana e outras dimensões da vida secular. Trata-se das experiências concretamente experimentadas que acontecem nos entre-lugares das culturas, o que abarca o cotidiano e as fronteiras das diferentes dimensões da vida.

Com essa visão, entendemos ser possível interpretar mais adequadamente as formas religiosas tradicionais e populares no país, suas diversidades internas, como uma tentativa de conferir a elas o peso que possuem, suas subjetividades e maneiras de reorganização simbólica, e sobretudo as formas de dupla ou múltipla pertença religiosa. Para os grupos cristãos, sobretudo católicos, por serem majoritários no Brasil, a compreensão das subjetividades que emergem da grande massa da população brasileira tem sido apresentada como um dos mais destacados desafios prático-pastorais. A antropóloga Silvia Fernandes, perguntada sobre que desafios os dados do censo representam para as igrejas, especialmente levando em conta o declínio numérico do catolicismo, afirmou:

Estamos falando de (re)construção de identidade religiosa que inclui dupla ou tripla pertença. As religiões tradicionais são desafiadas ao diálogo e abertura diante dos fiéis que estão nesse processo. A lógica do adepto é muito diferente da lógica institucional de pureza e vínculo e, por isso, enquanto a Igreja Católica e as denominações históricas do protestantismo adotam o reforço da doutrina como meio para o fortalecimento da identidade institucional em contexto de pluralismo religioso, os fiéis buscam elementos mais subjetivos, ainda que possam valorizar aspectos da tradição. O desafio é conciliar tradição com outros elementos que são próprios àqueles que vivem a experiência religiosa: novos símbolos; novas composições de crenças; novas práticas e experimentações etc. (FERNANDES, 2012, p. 1).

Superar a visão que reduz a religião a declarações formais e objetivas de pertença e compreendê-la no aspecto mais global e variado do cotidiano, com todas as fronteiras e entre-lugares que possui, além de se constituir um desafio para as igrejas tradicionais, abriria também novas possibilidades para os diálogos inter-religiosos, especialmente porque redesenharia os imaginários que o pluralismo religioso cria com a máxima "somos todos iguais". Nesse sentido, do mesmo modo que a reunião de grupos religiosos para diálogo e participação social conjunta pode, ao ocultar diferenciais de poder entre eles, gerar formas veladas de dominação, a compreensão moderna reducionista de 
religião, não devidamente aplicável aos grupos tradicionais, pode ser outra forma de artificialidade que afeta a identificação e consequente valorização da dupla ou múltipla pertença, assim como, também afeta os possíveis processos de diálogo inter-religioso.

A crítica à concepção religiosa moderna e ocidental, especialmente pela carga ideológica e de supremacia que possui, não deve imobilizar as aproximações de grupos de diferentes tradições religiosas. Pensadoras como a teóloga oriental Kwok Pui-Lan argumentam que as religiões que se organizam em contextos hegemônicos, como o cristianismo, a despeito dos séculos de abusos engendrados pelo colonialismo e da violência das posturas fundamentalistas ainda vigentes em nossos dias, têm uma contribuição importante para com o futuro da sociedade global. Todavia, é necessário que seja empreendido um movimento de descolonização da própria religião. Para tanto, tendo em vista a complexidade dos fenômenos religiosos atuais, para a autora "faz-se mister um exame mais acurado de como a religião é compreendida e de como as fronteiras religiosas têm sido construídas no Ocidente" [...] "A palavra não foi usada frequentemente até o Iluminismo, quando surgiu a necessidade de diferenciar o religioso do secular. Em seu uso moderno, a religião frequentemente conota uma série de crenças religiosas e uma comunidade institucionalizada" (PUI-LAN, 2015, p. 13). E a autora diz ainda:

Conforme vimos, na história do Ocidente, a ideia do outro diferente quanto à religião, rotulado quer de "pagão", que de "infiel”, quer de "bárbaro", tem sido usada como escada para reforçar a identidade cristã e a hegemonia europeia. A descoberta desse religioso outro caminhou de mãos dadas com o encontro da Europa com outras partes do mundo. As religiões mundiais do islamismo, hinduísmo, budismo e confucionismo são mapeadas em geografia distante e em países estranhos, nos quais as pessoas vivem com superstições e costumes bizarros. O agrupamento de populações enormes sob uma única rubrica religiosa, com características identificáveis, tornou mais fácil a gestão da diferença religiosa para o controle colonial. O diálogo interfé se beneficiaria das intuições de estudos pós-coloniais, que questionam como o eu e o outro, o centro e a periferia, o dominador cultural e o marginalizado foram construídos (PUI-LAN, 2015, p. 32-33).

O que temos realçado até aqui é o fato do conceito moderno de religião não dar conta de avaliações mais apuradas das religiões tradicionais e populares (SUNG, 2014). Isso dificulta em parte as análises da diversidade religiosa no país e das experiências de dupla ou múltipla pertença religiosa 
e as invisibilizam. Para isso, recorremos ao princípio pluralista. Tal visão está associada à perspectiva dos estudos culturais, que em solo latino-americano ganhou, a partir dos estudos, sobretudo do peruano Anibal Quijano e dos argentinos Enrique Dussel e Walter Mignollo, um novo conteúdo crítico. Trata-se da perspectiva ou giro decolonial.

Essas expressões, que se distinguem do "pós-colonial" ou do "descolonial", possuem um sentido estratégico que revela interpelações políticas e epistemológicas de reconstrução de culturas, instituições e relações sociais. Tais interpelações críticas são marcadas por certo caráter propositivo e prático e por ações concretas no âmbito cultural e político. O "decolonial" indica uma desobediência epistemológica sem a qual "não será possível o desencadeamento epistêmico e, portanto, permaneceremos no domínio da oposição interna aos conceitos modernos e eurocentrados, enraizados nas categorias de conceitos gregos e latinos e nas experiências e subjetividades formadas dessas bases" (MIGNOLO, 2008, p. 288).

A tarefa decolonial consiste em construir a vida a partir de outras categorias de pensamento que estão para além dos pensamentos ocidentais dominadores. Trata-se de uma postura e atitudes permanentes de transgressão e de intervenção no campo político e cultural, na incidência das culturas subalternalizadas e invisibilizadas, nas quais se pode identificar, visibilizar e incentivar lugares de exterioridade e de construções críticas alternativas e plurais. "O paradigma decolonial luta por fomentar a divulgação de outra interpretação que põe em evidência uma visão silenciada dos acontecimentos" e, ao mesmo tempo, revela "os limites de uma ideologia imperial que se apresenta como a verdadeira e única interpretação” (MIGNOLO, 2007, p. 457). Um princípio pluralista de análise é fundamental para a valorização das experiências de dupla ou de múltipla pertença religiosa.

\section{As múltiplas pertenças religiosas nos entre-lugares das culturas.}

Como temos visto até aqui, as experiências de dupla ou múltipla pertença são vivenciadas nas fronteiras, ou naquilo que Homi Bhabha, outro expoente dos estudos culturais, chamou de "entre-lugares" das culturas (BHABHA, 2001). O que temos levado em conta em nossas análises, especialmente quando nos referimos ao princípio pluralista, é a complexidade da realidade, não somente religiosa, mas também sociocultural. Há um ritmo acelerado das mudanças culturais em curso que engendram novas 
características no quadro de pluralismo. Os processos de globalização são amplos e diversos e acentuam a velocidade das alterações culturais, e geram certo ineditismo nas mais recentes configurações religiosas e nas crescentes formas de hibridismo, que se fortalecem nas áreas fronteiriças e nos entrelugares das culturas.

Em nossas análises, a dimensão de fronteira se realça por variadas razões. A primeira delas está ligada às intercomunicações entre diferentes experiências religiosas. A diversidade interna de cada tradição religiosa envolvida no conjunto das experiências religiosas e as relações assimétricas de poder que possuem na sociedade brasileira revelam espaços fronteiriços em boa parte inéditos e de difícil compreensão. Como exemplo disso, estão os pentecostalismos. Ainda são poucas as análises sobre as diferentes expressões pentecostais que olham atentamente para a diversidade delas, em geral ocasionadas por certa descontinuidade histórico-doutrinária delas com as tradicionais características das doutrinas cristãs, o que gera uma intensa diferença nas propostas. Por sua vez, o dado político-ideológico não é unívoco nos pentecostalismos, especialmente nos setores pobres da sociedade. Tal pluralidade acarreta diferentes formas de exercitar a fé, seja no campo político, nas compreensões éticas ou na visão a respeito dos espaços públicos. Isso ocorre no interior de uma mesma denominação religiosa, além das distinções entre elas, o que faz do quadro de pluralismo religioso mais diversificado do que usualmente imaginamos. Dimensões similares encontramos também em relação às expressões religiosas afro-brasileiras.

As fronteiras se dão também na medida em que as diferentes expressões religiosas no Brasil, assim como a diversidade interna de cada grupo religioso, possuem diferentes e mutáveis compreensões políticas e variadas visões de mundo, muitas vezes até mesmo antagônicas. Além disso, a maioria das experiências religiosas e inter-religiosas no país tem mantido ora um forte apelo de manutenção do status quo e ora é constituída de forte crítica social e estabelece, dessa forma, uma complexa relação entre religião, política e economia. Tais noções nos chamaram a atenção devido à busca que temos feito de um equacionamento mais adequado para as relações entre religião e cultura, que leve em conta a complexidade da realidade, a não linearidade das interações culturais e a emergência de novas realidades ambivalentes, entrecruzadas e híbridas. As duplas ou múltiplas pertenças religiosas se dão dentro de quadro de ambivalência cultural.

Para o debate das experiências de dupla ou múltipla pertença 
religiosa, é importante a referência a, pelo menos, dois aspectos. O primeiro, fundamental para os estudos de religião, se refere ao fato das identidades serem forjadas nas fronteiras, como nos mostram os estudos culturais. Assim, poderemos rever as formas dualistas, bipolares, quase maniqueístas de compreensão da realidade. O segundo, mais voltado para o campo práticopastoral, realça o horizonte hermenêutico e de intervenção social a partir da possibilidade de "negociação" da cultura ao invés de sua "negação", comum nas posições dicotômicas e bipolares, e a crítica às formas de invisibilização de culturas subalternas. As experiências religiosas de dupla ou múltipla pertença são portadoras dessas possibilidades.

Para uma compreensão mais adequada dos processos de múltipla pertença religiosa, e que, ao mesmo tempo, seja uma valorização deles, é importante pensá-los como uma temporalidade forjada nos entre-lugares e posicionada no "além”, que torna possível conceber a articulação de elementos antagônicos, ambivalentes ou contraditórios e possibilita novas realidades, ainda que sejam híbridas, sem forte coerência racional interna, mas nem por isso desprovida de potencial transformador e utópico. As identidades culturais nunca são retilíneas, estáveis, neutras ou puras. Os estudos de religião, especialmente no tocante ao pluralismo religioso, serão mais substancialmente desenvolvidos se recorrerem a tais referências. Há que se considerar sempre as ambivalências identitárias, a dimensão de não passividade dos atores sociais e as possibilidades de tradução entre os diferentes processos parciais de emancipação, que permitem criar sentido e direcionamentos concretos, ainda que precários, mas concretos.

O sociólogo português Boaventura de Souza Santos já nos chamara a atenção para este dado:

Sabemos hoje que as identidades culturais não são rígidas nem, muito menos, imutáveis. São resultados sempre transitórios e fugazes de processos de identificação. Mesmo as identidades mais sólidas, como a de mulher, homem, país africano, país latino-americano ou país europeu, escondem negociações de sentido, jogos de polissemia, choques de temporalidades em constante processo de transformação, responsáveis em última instância pela sucessão de configurações hermenêuticas que de época para época dão corpo e vida a tais identidades. Identidade são, pois, identificações em curso (SANTOS, 2010a, p. 135).

Homi Bhabha também contribui em direção similar. Para o autor: 
O que é teoricamente inovador e politicamente crucial é a necessidade de passar além das narrativas de subjetividades originárias e iniciais e de focalizar aqueles momentos ou processos que são produzidos na articulação de diferenças culturais. Esses "entrelugares" fornecem o terreno para a elaboração de estratégias de subjetivação - singular ou coletiva - que dão início a novos signos de identidade e postos inovadores de colaboração e contestação, no ato de definir a própria idéia de sociedade (BHABHA, 2001, p. 20).

Portanto, para a análise das duplas e múltiplas pertenças religiosas são de fundamental importância as interpretações conjuntivas da cultura, que reúnem e articulam as contradições presentes na globalidade, mas, sobretudo, não desconsideram o individual, o singular e concreto. Isso é inovador e politicamente importante, pois são nesses terrenos que ocorrem as novas estratégias de construção de identidades. Não obstante, é daí que brotam os novos signos que colaborarão e contestarão as definições e ideias a respeito das sociedades. As múltiplas pertenças religiosas nos dizem muito mais coisas do que imaginamos.

\section{A matriz religiosa e cultural brasileira como facilitadora da múltipla pertença religiosa.}

Ao analisarmos especificamente o campo das igrejas e dos movimentos cristãos, vemos que há no crescimento numérico dos grupos uma incidência intensa e direta de vários elementos provenientes da matriz religiosa e cultural brasileira. Esta, como se sabe, é marcada historicamente por elementos mágicos e místicos, fruto de uma simbiose das religiões indígenas, africanas e do catolicismo ibérico (BITTENCOURT FILHO, 2003). A avaliação do peso dos elementos místicos e mágicos provenientes das culturas indígenas, africanas e do catolicismo ibérico, que marcam a matriz religiosa brasileira, é fundamental nas análises científicas sobre o pluralismo religioso no Brasil, especialmente no tocante às experiências de dupla ou múltipla pertença religiosa. A experiência religiosa brasileira foi e tem sido fortemente influenciada por uma espiritualidade de cunho imagético e por narrativas míticas que se constituem por um conjunto de cosmovisões e experiências orientadas pela espontaneidade e sem maior rigor institucional do que por um corpus teológico sistematizado. Há que se dizer também que essa identidade religiosa é determinante do esvaziamento de expressões religiosas orientadas por discursos teológicos mais rígidos e formais, que não privilegiam a espontaneidade e a diferença cultural e, em certo sentido, explicam a expansão de movimentos no seio dos diversos grupos religiosos, que 
enfatizam o caráter espontâneo, místico e celebrativo. Sem possuir contornos fixos, os novos movimentos religiosos se multiplicam. De fato, esses movimentos possuem traços flutuantes, dispersos e plurais. Muitos deles situam-se nas fronteiras e cruzamentos da religião com a medicina, a arte, a física, a filosofia, a psicologia, a ecologia, e, especialmente, com a economia.

Há outro aspecto relevante. Trata-se da influência na vivência religiosa de perfis, não explicitamente religiosos, que formaram a mentalidade da sociedade moderna no final do século XX, como é o caso das ênfases no consumo, na vida privada, na ascensão social e aspectos econômicos similares. Talvez isso explique, pelo menos em parte, o sucesso dos livros e ideias de autores bastante difundidos no campo da autoajuda como Paulo Coelho e Lair Ribeiro, entre outros. Nesse sentido, se destacam também as "religiões de mercado", bastante evidenciadas em propostas no campo pentecostal, tanto nas versões protestantes como nas católico-romanas.

A lógica do mercado religioso torna-se um contraponto à adesão institucional de fiéis. A busca de sentido para a vida, preferencialmente no aspecto prático, uma vez mediada pelas ofertas de bens simbólicos, possibilita diferentes opções religiosas, algumas delas com dupla pertença. O mercado religioso de bens simbólicos, como produtor de sentido, está, de certa forma, aberto a todos. Por sua vez, diante da diversidade de ofertas dos bens simbólicos, as pessoas desejam soluções religiosas que ofereçam respostas rápidas, simples e eficazes e de mais fácil compreensão e com resultados comprováveis. Tais soluções possuem a capacidade de atrair um número maior de fiéis.

É importante dizer que não é somente no campo cristão que esse fenômeno se manifesta. Diferentes religiões, incluindo as de natureza afrobrasileira, como as umbandas, os candomblés e as encantarias, possuem vertentes que defendem formas de uma "espiritualidade de consumo". Nelas reside um caráter intimista, individualista e marcado pela busca de respostas imediatas para problemas pessoais ou familiares concretos que se revela na troca de esforços humanos (ofertas materiais e financeiras, atos religiosos como orações, bênção de objetos materiais e outros) por um retorno favorável aos desejos e necessidades humanas por parte do divino. Uma simples observação dos meios de comunicação social possibilita constatar o aumento do número de programas que utilizam os sistemas "0800" e "0900" para fins religiosos. 
Portanto, não se pode avaliar o pluralismo religioso e as experiências de múltipla pertença religiosa no Brasil sem levar em consideração atentamente os elementos que caracterizam a matriz cultural do país.

\section{Os diferentes tipos de múltipla pertença dentro do quadro de trânsito religioso.}

Outra realidade de destaque da pluralidade religiosa brasileira são os processos de trânsito religioso. Tais processos não estão desconectados das tendências do sistema econômico marcadas pela diversificação de ofertas, de práticas e de costumes, garantindo, como temos afirmado, a própria lógica e interesses sistêmicos. As formas de trânsito religioso são herança da autonomização dos indivíduos, que diante do enfraquecimento institucional das religiões, especialmente o cristianismo católico-romano, teriam ao seu dispor a possibilidade de comporem e recomporem suas próprias identidades religiosas. Por intermédio de uma considerável mobilidade, própria especialmente de realidades e culturas urbanas e marcadas pelas mídias, o fiel, transitando de um lugar a outro, uma vez livre para se (re)apropriar-abandonar elementos pertencentes a outras matrizes, o faz com vistas a compor seu próprio referencial simbólico-existencial.

O mais simples exemplo de trânsito que identificamos é a mudança de pertença religiosa. Isso pode ser dar no exemplo de um cristão que se torna espírita, budista ou islâmico - e não tem sido raro esse fenômeno no Brasil -, ou de alguém que deixa a pertença religiosa da Umbanda para assumir a cristã, ou vice-versa, ou mesmo a passagem dentro do universo cristão de uma confissão católica para uma de natureza evangélica.

O trânsito religioso também se configura por intermédio dos casos de dupla ou múltipla pertença religiosa, e são esses que nos interessam aqui mais diretamente. Em certo sentido, eles revelam um processo de suplantação das lógicas exclusivistas que imperaram no decorrer dos séculos XIX e XX, e que agora apresentam traços de certo esgotamento. A despeito das identidades religiosas tradicionais que se alicerçavam em doutrinas e nos dogmas que caracterizam as comunidades, a experiência religiosa contemporânea se configuraria a partir de um alto teor de plasticidade. Isso se dá de tal modo que "a ideia de que os diferentes sistemas religiosos particulares são complementares, e não excludentes, parece constituir uma das marcas preponderantes da sociedade contemporânea" (STEIL, 2008, p. 10). Desse modo, malgrado os fenômenos fundamentalistas, haveria uma 
espécie de complementaridade entre as experiências religiosas e não somente competição entre elas.

As situações são variadas e de difícil descrição. Há as experiências nas quais uma mesma pessoa, sem trocar de religião, se identifica simultaneamente com outro ou mais grupos. É o que Sandra Duarte de Souza (2001) denomina "trânsito pertencente", o que se constitui nos casos em que o sujeito declara determinada pertença, mesmo admitindo experimentar outras expressões religiosas. É comum católicos frequentarem sessões espíritas kardecistas. Ou um espírita que em determinados momentos frequenta, as vezes assiduamente, cultos evangélicos, missas católicas ou terreiros de Umbanda. Isso é bastante comum no quadro religioso brasileiro.

Há casos em que a pessoa mesmo ao professar uma religião, exerce a outra. Isso se dá nos casos, em especial de religiões afro, onde, por uma série de fatores, mas, sobretudo, o preconceito, seus adeptos e adeptas, apesar de frequentarem e pertencerem a determinada religião de matriz africana, afirmam professar a fé católica. Nos censos das décadas de 1940 e 50, esse fato já era comum entre adeptos da Umbanda e do Candomblé, que se declaravam católicos ou espíritas para não serem perseguidos pela polícia, que considerava tais religiões como práticas ilegais. Hoje, esse tipo de perseguição religiosa, ao menos nesses moldes, já quase não existe, embora haja outras formas de discriminação, mas, mesmo assim, essa postura ainda persiste. Ela poderia explicar, entre outras razões, o baixo registro das tradições religiosas afro-brasileiras de apenas 3\% da população brasileira (CAMURÇA, 2014, p. 14). Como são visíveis os traços e as marcas culturais das experiências religiosas afro-brasileiras no país, a dupla pertença nesse perfil certamente é bastante intensa.

Tem sido crescente, embora permaneçam minoritários ou invisibilizados, os casos de harmonização de uma dupla ou múltipla pertença, dando valor igual ou similar às expressões religiosas envolvidas nesse pertencimento. Ou seja, crescem os relatos de pessoas que se se afirmam como pertencentes simultaneamente ao Catolicismo e ao Candomblé, ou ao Espiritismo e ao Movimento Hare Krishna, e, até mesmo, o que era raro na cultura brasileira, mas agora tem surgido, a dupla pertença protestanteafro-brasileira.

Há também um tipo de múltipla pertença, fruto do que foi chamado de "trânsito sem pertença" ou "trânsito de pertença provisória", que ocorre quando não há aderência a qualquer religião específica ou a qualquer grupo 
ou confissão por parte do sujeito religioso. Devido ao alto grau de volatilidade dessas experiências e dada a relativização do poder institucional e das novas forças culturais, especialmente a econômica, o indivíduo em sua mobilidade religiosa "combina e reinventa tradições, estabelece sínteses provisórias, cria uma cosmovisão aquosa, adaptável às mudanças temporárias" (SOUZA, 2001, 166).

Há um quinto tipo - que também gostaríamos de denominar "múltipla pertença" - que se caracteriza pelo deslocamento de aspectos filosóficos ou ideológicos, visões de mundos e práticas que advêm de determinada cultura religiosa e incide em outra, quase sempre de forma inconsciente e não explícita. Em outras palavras, vive-se uma religião, mas se professa outra. Trata-se do movimento de ressignificação de realidades e de cosmovisões, na medida em que o indivíduo, sem mudar de religião, compõe sua identidade religiosa a partir de elementos de outras matrizes. Isso não é privilégio desta ou daquela religião, mas ele é mais comum entre religiosidades mais acentuadamente "porosas" e menos institucionalizadas, e por isso mais flexíveis em suas interfaces culturais. É comum entre os grupos pentecostais brasileiros, por exemplo, encontrarmos elementos da cultura religiosa afrobrasileira ou do catolicismo popular, agora redimensionados em outra roupagem religiosa. Compreendemos que tal reconfiguração representa também uma forma de dupla ou múltipla pertença religiosa.

\section{Considerações finais}

O debate em torno das experiências de dupla ou múltipla pertença religiosa tem despertado a atenção tanto dos setores acadêmicos quanto de grupos e lideranças religiosas. É fato que por serem experiências em geral ocultadas e/ou invisibilizadas são, por isso mesmo, pouco avaliadas. Ao mesmo tempo, reconhecemos que se trata de um aspecto do quadro de pluralismo religioso no Brasil de difícil compreensão e análise, e que nossas contribuições, embora apresentadas a partir de eixos que consideramos relevantes para um aprofundamento da questão, são limitadas e insuficientes. De qualquer forma, nosso esforço nos mostrou que as múltiplas pertenças religiosas nos revelam situações e questões da esfera social muito mais complexas do que imaginamos.

Apresentamos cinco elementos que, em nossa compreensão, uma vez assimilados, contribuiriam bastante para o debate nessa temática. Eles estão reproduzidos a seguir. 
Primeiro: maior atenção ao destaque que o crescente quadro de pluralismo religioso tem para a vida das pessoas e grupos, o que lhes possibilita maiores informações e mais fácil acesso às diferentes propostas religiosas. Ou seja, quanto mais se valoriza e se explicita o pluralismo, tanto mais se multiplicam as experiências de múltipla pertença.

Segundo: a importância de se pensar criticamente o quadro de pluralismo religioso, não a partir do conceito moderno de religião, em geral compartimentalizado, racionalizado e formal, mas a partir de como se dá efetivamente a relação entre vida cotidiana e expressões de fé.

Terceiro: a valorização das experiências de múltiplas pertenças religiosas, por serem vividas em espaços de fronteiras e nos entre-lugares das culturas. Consideramos que, para a análise das duplas e múltiplas pertenças religiosas, são de fundamental importância as interpretações conjuntivas da cultura, que reúnem e articulam as contradições presentes na globalidade, mas, sobretudo, não desconsidera o individual, o singular e concreto. Isso é inovador e politicamente importante, pois são nesses terrenos que ocorrem as novas estratégias de construção de identidades. É daí que brotam os novos signos que colaborarão e contestarão as definições e ideias sobre as sociedades. As múltiplas pertenças religiosas nos dizem muito mais coisas do que imaginamos.

Quarto: o reconhecimento de que a matriz cultural e religiosa brasileira, devido ser ela marcada historicamente por elementos mágicos e místicos, fruto de uma simbiose das religiões indígenas, africanas e do catolicismo ibérico, facilita os processos de dupla ou múltipla pertença religiosa.

Quinto: a constatação de que o trânsito religioso se dá, não apenas na migração de uma religião para a outra, mas também na recomposição simbólico-cultural de diferentes sistemas de crenças, o que torna um fator gerador de dupla ou múltipla pertença. Desse modo, diferentes tipos podem ser caracterizados: o das pessoas que afirmam determinada pertença e admitem experimentar outras expressões religiosas, as pessoas que declaram uma religião, mas por algum motivo exercem outra, as pessoas que vivenciam de forma integrada mais de uma tradição religiosa, as pessoas que não aderem a uma religião específica, mas transitam por mais de uma, e aquelas que, mesmo mantendo a sua pertença religiosa, articulam elementos simbólicorituais de outras religiões.

Esperamos que estas considerações possam contribuir com o debate a respeito do tema, desejando que os demais aspectos sobre o quadro de 
pluralismo religioso no Brasil sejam enriquecidos pelos elementos que indicamos. As duplas e as múltiplas pertenças religiosas são experiências desafiadoras, não somente para o campo de estudos da religião, quanto também para grupos religiosos que se interessam em repensar suas práticas e estratégias de ação em consonância com a realidade cultural e religiosa que permeia a vida social.

\section{Referências}

AMALADOSS, Michael. Pela estrada da vida: prática do diálogo inter-religioso. São Paulo: Paulinas, 1995.

ARAGÃO, Gilbráz de Souza. "Perspectivas transreligiosas e o estudo das religiões" (p. 39-59). In: RIBEIRO, Claudio de Oliveira (org.). Espiritualidades contemporâneas, pluralidade religiosa e diálogo. São Paulo: Fonte Editorial, 2016.

BENJAMIN, Walter. O capitalismo como religião. São Paulo: Boitempo, 2013.

BITTENCOURT FILHO, José. Matriz Religiosa Brasileira: religiosidade e mudança social. Petrópolis-RJ: Vozes, 2003.

CAMURÇA, Marcelo. A religião e o Censo: enfoques metodológicos. Uma reflexão a partir das consultorias do ISER ao IBGE sobre o dado religioso nos Censos. Comunicações do Iser (69), set. 2014.

FERNANDES, Sílvia. "A (re)construção da identidade religiosa inclui dupla ou tripla pertença.” Revista IHU On-Line, jul. 2012. Disponível em: http://www.ihu.unisinos.br/ entrevistas/511249-estamos-falando-de-re-construcao-de-identidade-religiosa-entrevistaespecial-com-silvia-fernandes.

GIUMBELLI, Emerson Giumbelli. “O campo religioso em suas configurações.” In: SENA, Emerson \& SOFIATI, Flávio. Novas Leituras do Campo Religioso Brasileiro. São Paulo: Ideias \& Letras, 2014.

HALL, Stuart. Formations of Modernity. Oxford, UK, Blackwell Publishers Ltd., 1992.

MIGNOLO, Walter. "Delinking. The rethoric of modernity, the logic of coloniality and the grammar of de-coloniality.” In: Cultural studies, n. 21, v. 2 e 3. Routledge, 2007.

MIGNOLO, Walter. "Desobediência epistêmica: a opção descolonial e o significado de identidade em política." Cadernos de Letras da UFF - Dossiê: literatura, língua e identidade, n. 34, 2008.

PUI-LAN, Kwok. Globalização, gênero e construção da paz: o futuro do diálogo interfé. São Paulo: Paulus, 2015.

RIBEIRO, Claudio de Oliveira. "O princípio pluralista: bases teóricas, conceituais e possibilidades de aplicação.” Revista de Cultura Teológica, v. 25, p. 234-254, 2017.

SANTOS, Boaventura de Souza. Pela mão de Alice: o social e o político na pós-modernidade. São Paulo: Cortez, 2010. 
SOUZA, Sandra Duarte de. Trânsito religioso e construções simbólicas temporárias: uma bricolagem contínua. In: Estudos de Religião, SBC: UMESP, v. 15, n. 20, jan./jul. 2001.

STEIL, Carlos Alberto. "Oferta simbólica e mercado religioso na sociedade global." In: MOREIRA, Alberto da Silva \& DIAS DE OLIVEIRA, Irene (orgs.). O Futuro da Religião na Sociedade Global. São Paulo-SP: Paulinas/UCG, 2008.

SUNG, Jung Mo. "Capitalism as religion and religious pluralism: an approach from Liberation Theology.” Buddisth-Christian Studies, v. 34, 2014, p. 155-165.

Submetido em: 5-11-2018

Aceito em: 25-11-2018 